\title{
Serum Cytokine Profiles Differentiating Hemorrhagic Fever with Renal Syndrome and Hantavirus Pulmonary Syndrome
}

\author{
Svetlana F. Khaiboullina ${ }^{1,2,3+}$, Silvana Levis ${ }^{4 \dagger}$, Sergey P. Morzunov, \\ Ekaterina V. Martynova ${ }^{2}$, Vladimir A. Anokhin ${ }^{6}$, Oleg A. Gusev ${ }^{2,7}$, Stephen C. St Jeor $^{3}$, \\ Vincent C. Lombardi ${ }^{1,2 *}$ and Albert A. Rizvanov ${ }^{2 *}$
}

OPEN ACCESS

Edited by:

Marina I. Arleevskaya,

Kazan State Medical Academy, Russia

Reviewed by: Colleen B. Jonsson, University of Tennessee,

Knoxville, USA

Jan Clement,

University Hospitals Leuven, Belgium

Alexei B. Shevelev,

Emanuel Institute of Biochemical Physics Russian Academy of

Sciences, Russia

${ }^{*}$ Correspondence:

Vincent C. Lombardi vclombardi@nvcbr.org;

Albert A. Rizvanov

albert.rizvanov@kpfu.ru

tThese authors have contributed equally to this work.

Specialty section: This article was submitted to Microbial Immunology, a section of the journal Frontiers in Immunology

Received: 06 January 2017 Accepted: 27 April 2017

Published: 18 May 2017

Citation:

Khaiboullina SF, Levis S,

Morzunov SP, Martynova EV, Anokhin VA, Gusev OA, St Jeor SC, Lombardi VC and Rizvanov AA (2017)

Serum Cytokine Profiles

Differentiating Hemorrhagic Fever with Renal Syndrome and Hantavirus

Pulmonary Syndrome.

Front. Immunol. 8:567.

doi: 10.3389/fimmu.2017.00567
${ }^{1}$ Nevada Center for Biomedical Research, Reno, NV, USA, ${ }^{2}$ Institute of Fundamental Medicine and Biology, Kazan Federal University, Kazan, Russia, ${ }^{3}$ Department of Microbiology and Immunology, University of Nevada School of Medicine, Reno, NV, USA, ${ }^{4}$ Instituto Nacional de Enfermedades Virales Humanas "Dr. Julio I. Maiztegui", Pergamino, Argentina, ${ }^{5}$ Department of Pathology, University of Nevada School of Medicine, Reno, NV, USA, ${ }^{6}$ Kazan State Medical University, Kazan, Russia,

${ }^{7}$ Preventive Medicine and Diagnosis Innovation Program, Center for Life Science Technologies, Yokohama, Japan

Hantavirus infection is an acute zoonosis that clinically manifests in two primary forms, hemorrhagic fever with renal syndrome (HFRS) and hantavirus pulmonary syndrome (HPS). HFRS is endemic in Europe and Russia, where the mild form of the disease is prevalent in the Tatarstan region. HPS is endemic in Argentina, as well as other countries of North and South American. HFRS and HPS are usually acquired via the upper respiratory tract by inhalation of virus-contaminated aerosol. Although the pathogenesis of HFRS and HPS remains largely unknown, postmortem tissue studies have identified endothelial cells as the primary target of infection. Importantly, cell damage due to virus replication, or subsequent tissue repair, has not been documented. Since no single factor has been identified that explains the complexity of HFRS or HPS pathogenesis, it has been suggested that a cytokine storm may play a crucial role in the manifestation of both diseases. In order to identify potential serological markers that distinguish HFRS and HPS, serum samples collected during early and late phases of the disease were analyzed for 48 analytes using multiplex magnetic bead-based assays. Overall, serum cytokine profiles associated with HPS revealed a more pro-inflammatory milieu as compared to HFRS. Furthermore, HPS was strictly characterized by the upregulation of cytokine levels, in contrast to HFRS where cases were distinguished by a dichotomy in serum cytokine levels. The severe form of hantavirus zoonosis, HPS, was characterized by the upregulation of a higher number of cytokines than HFRS (40 vs 21). In general, our analysis indicates that, although HPS and HFRS share many characteristic features, there are distinct cytokine profiles for these diseases. These profiles suggest a strong activation of an innate immune and inflammatory responses are associated with HPS, relative to HFRS, as well as a robust activation of Th1-type immune responses. Finally, the results of our analysis suggest that serum cytokines profiles of HPS and HFRS cases are consistent with the presence of extracellular matrix degradation, increased mononuclear leukocyte proliferation, and transendothelial migration.

Keywords: hemorrhagic fever with renal syndrome, hantavirus pulmonary syndrome, nephropathia epidemica, cytokine profile, blood serum 


\section{INTRODUCTION}

Hantaviruses are negative strand RNA viruses carried by rodents, insectivores, and bats. The epidemiology of hantaviruses reflects the distribution of their primary rodent hosts (1) and can be divided into two groups based on clinical manifestation in human: hantavirus pulmonary syndrome (HPS) and hemorrhagic fever with renal syndrome (HFRS). HPS is endemic in America and diagnosed in many countries including Argentina and USA $(2,3)$. Several hantaviruses, including Andes and Sin Nombre, were linked to HPS (1). In contrast, HFRS is exclusively diagnosed in Europe and Asia $(1,4,5)$. In Europe, a mild form of HFRS, also referred as nephropathia epidemic (NE), is clinically distinguished $(6,7)$. HFRS/NE is diagnosed in many countries in Europe, including Western part of Russia, where endemically active regions include the republic of Tatartsan (8). Puumala virus (PUUV) is primarily identified as the causative agent of HFRS/ NE in Tatarstan (9).

Hantaviruses cause asymptomatic infection in their rodent hosts, whereas in human, infection with Andes, Sin Nombre, and Puumala can result in an acute and sometimes fatal disease. It is believed that humans acquire infection by inhaling viruscontaminated aerosols (10). As a general rule, humans can only become infected after direct contact with infected rodents or their excreta; however, there has been documented cases of Andes virus being spread from person-to-person $(11,12)$.

Hantavirus pulmonary syndrome is an acute severe disease characterized by pneumonia, cardiovascular failure, and shock (13). As the respiratory symptoms worsen, the disease progresses into the cardiopulmonary phase characterized by respiratory distress. In a few hours, patients become hypotensive and develop tachycardia, which can lead to cardiovascular shock (13). Additionally, some patients will present with hemorrhagic manifestations $(14,15)$. The convalescent phase can last for months, especially in patients requiring mechanical ventilation. It has been suggested that the rates of HPS fatalities vary with the hantavirus strain. For example, Figueiredo et al. reported that the hantavirus strain Araraquara is associated with a more severe presentation of HPS as compared to the Juquitiba strain (15).

Clinically, HFRS manifests with bleeding disorders and kidney dysfunction (16-18). Later, hemorrhages appear, which vary from small petechia to severe internal bleeding $(16,17)$. In some severe cases, disseminated intravascular coagulation syndrome can develop, which is considered as one of the primary causes of death in HFRS (19). Kidney pathology is present in all cases, progressing through several stages of kidney dysfunction including oliguria, polyuria, and convalescent $(18,20)$.

In vitro studies and postmortem observations have shown that hantaviruses are not cytopathic (21-24). Therefore, HPS and HFRS pathogenesis cannot be explained by direct tissue damage due to viral replication. Reactions of the organism to hantavirus infection, particularly the control of inflammatory cytokine expression, have been suggested as a key factor in disease pathogenesis. In accordance, an increased tissue infiltration with mononuclear leukocytes is a hallmark of HPS and HFRS (23-25). It has been suggested that the leukocyte infiltration, found in postmortem HPS and HFRS tissues, may be the result of an increased expression of inflammatory cytokines $(24,26)$. Additionally, high serum levels of inflammatory cytokines have been described for both HPS and HFRS (27-29). Furthermore, it appears that the severity of the disease associates with proinflammatory cytokine expression in patients with hantavirus infection. For example, Saksida et al. demonstrated that the level of serum pro-inflammatory cytokines was higher in HFRS patients infected with Dobrava virus as compared to PUUV-infected patients (30). Additionally, our previous report points out the potential role of Th1-type immune response in the severity of NE (28). PUUV infection presents with a milder form of the disease and lower mortality rate when compared to Dobrava virus infections. Therefore, it could be suggested that inflammatory cytokine expression may determine the severity of clinical presentations and, potentially impact the mortality rates $(6,31)$.

In the present study, our analyses revealed that distinct cytokine profiles associated with HPS and HFRS. The HPS profile was suggestive of severe inflammatory responses when compared to that of HFRS. Additionally, our data demonstrate that HPS is characterized by the upregulation of Th1-type immune response early during infection. Pronounced upregulation of cytokines that facilitate innate immune response, especially natural killer (NK) cell function, was also observed in HPS cases relative to HFRS. Furthermore, activation of a mixed population of immune effector cells, including mononuclear and segmented leukocyte, is predicted in HPS cases based on the cytokine profile. Finally, the observed HPS and HFRS serum cytokine profiles are consistent with disease pathology characterized by increased mononuclear leukocyte proliferation, transendothelial migration, and degradation of extracellular matrix.

\section{MATERIALS AND METHODS}

\section{Subjects}

One set of samples consisted of sera collected in Argentina during HPS outbreaks in Buenos Aires, Santa Fé, Entre Ríos, and Jujuy provinces. Of the 40 HPS serum samples from 30 total subjects ( $34 \pm 3.5 ; 26$ male, 4 female), 7 individual samples were from fatal cases, 29 were collected from those who survived, and no information was available with respect to the outcome of the other 4 . Out of the 29 samples from survivors, serum samples from three cases were collected once at the early stage of the disease, and two sets of serum samples were collected from 13 patients, once during the early stage and once at a late stage of the disease.

Sixty-seven HFRS serum samples ( $38 \pm 4.6 ; 52$ male, 15 female) were collected from patients admitted into Republican Clinical Hospital for Infectious Disease, Republic of Tatarstan. Serum from 33 HFRS cases was collected twice (early and convalescent), while a single serum sample was obtained from one patient. Diagnoses of HFRS and HPS were based on clinical presentation and were serologically confirmed by detection of anti-hantavirus antibodies. In some cases, the diagnosis was confirmed by PCR. Serum samples from 55 healthy individuals $(37 \pm 5.1 ; 32$ males, 13 females) matched by age, gender, and region were collected and served as controls. Samples collected in the Russian Federation 
were done so under a protocol approved by the Institutional Review Board of the Kazan Federal University and informed consent was obtained from each respective subject according to the guidelines approved under this protocol (Article 20, Federal Law "Protection of Health Right of Citizens of Russian Federation" N323-FZ, 11.21.2011). Sample collection in Argentina was made under a protocol approved by the Institutional Review Board of the Instituto Nacional de Enfermedades Virales Humanas Argentina.

\section{Multiplex Analysis}

Serum cytokine levels were analyzed using multiplex magnetic bead-based antibody detection kits following the manufacturer's instructions (Bio-Rad, Hercules, CA, USA). In order to survey 48 individual analytes, the Bio-Plex Pro Human Cytokine 27-plex and 21-plex immunoassay kits were used. For each subject, $50 \mu \mathrm{l}$ of serum was analyzed on a Luminex 200 analyzer (Luminex, Austin, TX, USA) utilizing MasterPlex CT control software and MasterPlex QT analysis software (MiraBio, San Bruno, CA, USA). The median fluorescence intensities were determined using a minimum of 50 beads per analyte and serum concentrations were calculated using standard curves for each analyte generated with standards provided with the Bio-Plex kit. Each serum sample was analyzed in duplicates.

\section{Cytokine Network and Functional Analysis}

Ingenuity Pathway Analysis (IPA) Software and DAVID 6.7 Software (32) packages were used independently, to examine cytokine-based enrichment of molecular pathways. The list of genes coding significantly altered cytokines (with threshold of \pm 2 -fold in the average value of the cytokine level, $P$ value $<0.05$ ) were used and the pathways showing the enrichments with significance of $P<0.05$ were identified and analyzed. Both platforms provided corroborative results and the same significantly enriched pathways lists.

\section{FANTOM5 Analysis}

Raw cytokine levels, measured using the Bio-Plex system, were first normalized against the median level of the 48 cytokines in each sample. Per group median normalization was then carried out for two separate groups, Argentina (Andes) and Tartarstan (HFRS). For each cytokine/group, the level of a given cytokine was normalized to the median level across the group (including both controls and cases). In the Argentina and Tartarstan groups, there were also subgroups corresponding to sera taken upon admission to the hospital and sera taken upon discharge. The median fold changes were compared between cases and controls for each group or subgroup. Expression profiles of the upregulated cytokines were manually examined in the FANTOM5 datasets (PMID: 24670764, PMID: 25678556), to determine what primary cell types they are expressed by and whether they are induced upon pathogenic stimuli.

\section{Statistical Analysis}

Statistical analysis was performed using Statistica and XLSTAT software (StatSoft, Tulsa, OK, USA, and Addinsoft, New York, NY, USA, respectively). Statistical analysis was performed using
Student's $t$-test for comparisons between individual experimental groups. Data are presented as mean $<\mathrm{SE}$. Significance was established at a value of $P<0.05$.

\section{RESULTS}

\section{Serum Samples}

Hantavirus pulmonary syndrome and NE serum samples were collected at different time points during hospitalization. Due to the nature of the disease, two-time point collection was not always feasible. For example, only a single serum sample was collected from each of the seven fatal HPS cases. The majority of HPS samples (12 samples) from Argentina were collected upon admission to the hospital, while a small number of samples (seven samples) were also obtained before discharge. NE and HPS sera were obtained as clinical surplus material; therefore, no patient identifiers were available to match the first and second samples. Information provided was limited to diagnosis and virus strain. HPS sera from Argentina were mostly Lechiguanas strain, with the exception of three samples confirmed by PCR to be the Orán strain. HFRS samples were collected in the Republic of Tatarstan, an area identified as endemic for Puumala hantavirus (8). Based on these data, we partitioned the serum samples into Andes and PUUV infections.

\section{Serum Cytokine Profile HPS Cases from Argentina}

Two sets of HPS serum samples were collected, early at the time of hospitalization (7.05 \pm 0.98 days) and during the convalescent period (42.2 \pm 6.9 days). Serum levels of 41 cytokines were upregulated during the early stage of the disease (Table 1). The majority of these cytokines, a total of 35 , remained upregulated at the late stage disease. For most of the cytokines, serum concentration had declined by the late stage, while levels of some cytokines remained upregulated (CXCL1, LIF, CXCL9, TNF $\beta$ ) or was further elevated (CXCL10, CCL2, IL-1 $\alpha$, IL-2RA, IL-3, IL-12p40, CCL27, CCL7, bNGF, SCF, TRAIL). When early- and late-stage serum cytokine levels were compared, the only significant differences detected were in the concentrations of CXCL10 and MCSF. Interestingly, higher CXCL10 and lower MCSF levels were found in the late stage serum as compared to that in early time points of the disease.

Serum samples from seven fatal HPS cases were collected upon admission to the hospital. The average date of serum collection from fatal cases was $6.1 \pm 1.18$, which is close to those collected in early phase non-fatal cases $(7.05 \pm 0.98$ days $)$. Therefore, early phase of non-fatal cases and fatal cases could be compared (Table 2). Serum levels of 30 cytokines were upregulated in fatal HPS cases. Although the majority of these cytokines overlapped with those upregulated in non-fatal cases, there were cytokines uniquely elevated in fatal cases. For example, IL-2, IL-2RA, IL-4, IL-7, IL-17A, CCL4, CCL11, CCL27, bFGF, PDGF-BB, TNF $\alpha$, and VEGF (Table 1) were upregulated in non-fatal cases, while IL-6 was significantly upregulated only in fatal cases when compared to healthy controls (Table 2). When cytokines upregulated in fatal and non-fatal cases were compared, significant differences in 
TABLE 1 | Serum cytokine levels in early and late hantavirus pulmonary syndrome (HPS).

\begin{tabular}{|c|c|c|c|c|c|c|}
\hline Analyte & Control ( $n=10 ; \mathrm{pg} / \mathrm{ml})$ & HPS early $(n=16 ; \mathrm{pg} / \mathrm{ml})$ & HPS late $(n=13 ; \mathrm{pg} / \mathrm{ml})$ & $P^{*}$ & $P^{*}$ & $P^{\#}$ \\
\hline $\mathrm{IL}-1 \alpha$ & $86.7 \pm 9.1$ & $393.3 \pm 10.7$ & $411.1 \pm 18.9$ & 0.0001 & 0.0001 & \\
\hline IL-1RA & $327.4 \pm 62.5$ & $1,134.0 \pm 408.1$ & $657.4 \pm 210.6$ & 0.002 & & \\
\hline $\mathrm{IL}-2^{\mathrm{a}}$ & $17.5 \pm 1.7$ & $88.5 \pm 44.5$ & $20.6 \pm 1.9$ & 0.005 & & \\
\hline IL-2RA ${ }^{a}$ & $138.7 \pm 12.2$ & $1,375.0 \pm 122.5$ & $1,426.9 \pm 489.9$ & 0.0001 & 0.0001 & \\
\hline IL-3 & $82.1 \pm 11.7$ & $2,444.9 \pm 215.4$ & $2,595.9 \pm 661.4$ & 0.0001 & 0.0001 & \\
\hline $\mathrm{IL}-4^{\mathrm{a}}$ & $8.8 \pm 8.8$ & $21.9 \pm 5.1$ & $12.7 \pm 1.2$ & 0.0001 & 0.01 & \\
\hline IL-7 $7^{a}$ & $67.9 \pm 4.9$ & $130.0 \pm 31.2$ & $94.9 \pm 3.5$ & 0.002 & 0.02 & \\
\hline IL-9 & $25.8 \pm 3.1$ & $85.4 \pm 20.5$ & $56.7 \pm 12.3$ & 0.0001 & 0.0008 & \\
\hline IL-10 & $45.2 \pm 4.9$ & $186.8 \pm 101.8$ & $101.8 \pm 15.8$ & 0.01 & 0.0001 & \\
\hline IL-12p40 & $159.7 \pm 23.5$ & $4,295.9 \pm 513.1$ & $4,732.8 \pm 1,324.4$ & 0.0001 & 0.0001 & \\
\hline IL-12p75 & $44.6 \pm 4.6$ & $100.0 \pm 14.7$ & $79.8 \pm 6.4$ & 0.0001 & 0.002 & \\
\hline IL-13 & $52.4 \pm 4.0$ & $97.4 \pm 21.1$ & $77.3 \pm 2.6$ & 0.001 & 0.01 & \\
\hline IL-15 & $33.2 \pm 2.7$ & $68.2 \pm 14.1$ & $51.3 \pm 3.2$ & 0.0003 & 0.007 & \\
\hline IL-16 & $169.3 \pm 35.8$ & $2,759.3 \pm 295.2$ & $2,586.8 \pm 625.5$ & 0.0001 & 0.0001 & \\
\hline IL-17A ${ }^{a}$ & $84.7 \pm 15.7$ & $208.9 \pm 30.9$ & $172.3 \pm 21.7$ & 0.0003 & 0.02 & \\
\hline IL-18 & $444.4 \pm 71.3$ & $854 \pm 60.2$ & $784 \pm 143$ & 0.003 & & \\
\hline CCL2 & $173.4 \pm 17.0$ & $265.2 \pm 34.7$ & $460.8 \pm 111.7$ & 0.01 & 0.0001 & \\
\hline CCL4 & $136.6 \pm 14.4$ & $381.3 \pm 138.9$ & $212.9 \pm 26.8$ & 0.003 & 0.03 & \\
\hline CCL7 & $128.9 \pm 22.6$ & $455.3 \pm 71.4$ & $579.6 \pm 221.9$ & 0.0001 & 0.0001 & \\
\hline CCL11 ${ }^{a}$ & $85.9 \pm 8.9$ & $202.0 \pm 62.2$ & $140.3 \pm 26$ & 0.002 & 0.02 & \\
\hline $\mathrm{CCL} 27^{\mathrm{a}}$ & $836.3 \pm 233.7$ & $1,550.0 \pm 76.6$ & $1,664.2 \pm 82.5$ & 0.005 & 0.01 & \\
\hline CXCL1 & $404.8 \pm 69.4$ & $1,181.5 \pm 100.4$ & $1,025.5 \pm 70.4$ & 0.0001 & 0.0003 & \\
\hline CXCL9 & $734.8 \pm 140.5$ & $1,949.4 \pm 136.5$ & $1,911.5 \pm 368.2$ & 0.0001 & 0.002 & \\
\hline CXCL10 & $415.3 \pm 77.5$ & $2,383.9 \pm 600.8$ & $5,188.1 \pm 981.2$ & 0.0001 & 0.0001 & 0.013 \\
\hline CXCL12 & $213.7 \pm 23.9$ & $3,577.9 \pm 116.3$ & $3,404.8 \pm 145.6$ & 0.0001 & 0.0001 & \\
\hline bFGFa & $42.3 \pm 5.4$ & $108.5 \pm 27.9$ & $65.9 \pm 5.8$ & 0.0005 & & \\
\hline bNGF & $79.9 \pm 10.3$ & $278.3 \pm 16.6$ & $305.9 \pm 42.1$ & 0.0001 & 0.0001 & \\
\hline GMCSF & $42.9 \pm 5.9$ & $174.6 \pm 68.9$ & $82.5 \pm 13$ & 0.001 & 0.01 & \\
\hline HGF & $705.6 \pm 134.5$ & $3,059.5 \pm 333.7$ & $2,319.3 \pm 434.5$ & 0.0001 & 0.0001 & \\
\hline $\mathrm{IFN} \alpha$ & $71.0 \pm 7.3$ & $466.9 \pm 30.7$ & $387.4 \pm 85.7$ & 0.0001 & 0.0001 & \\
\hline $\mathrm{IFN} \gamma$ & $69 \pm 11.9$ & $190.1 \pm 41.9$ & $171.5 \pm 19.2$ & 0.0003 & 0.0008 & \\
\hline LIF & $177.7 \pm 24.1$ & $742.5 \pm 57.2$ & $708.5 \pm 109.1$ & 0.0001 & 0.0001 & \\
\hline MCSF & $206.3 \pm 30.9$ & $876.9 \pm 59.5$ & $607.3 \pm 106.2$ & 0.0001 & 0.0001 & 0.02 \\
\hline MIF & $229.5 \pm 59.1$ & $1,781.1 \pm 308.5$ & $1,072.1 \pm 111.9$ & 0.0001 & 0.0001 & \\
\hline PDGF-BBa & $1,759.8 \pm 124.5$ & $2,568.6 \pm 307.3$ & $2,057.7 \pm 316.9$ & 0.005 & & \\
\hline SCF & $268.3 \pm 39.9$ & $1,308.1 \pm 78.8$ & $1,436.9 \pm 268.9$ & 0.0001 & 0.0001 & \\
\hline SCGFb & $2,037.4 \pm 370.3$ & $37,608.9 \pm 1796.4$ & $31,720.5 \pm 2857.5$ & 0.0001 & 0.0001 & \\
\hline $\mathrm{TNF} \alpha^{\mathrm{a}}$ & $84.4 \pm 10.3$ & $234.9 \pm 42.9$ & $199.5 \pm 19.9$ & 0.0001 & 0.0001 & \\
\hline $\mathrm{TNF} \beta$ & $84.3 \pm 11.0$ & $264.1 \pm 20.7$ & $272.4 \pm 54.3$ & 0.0001 & 0.0001 & \\
\hline TRAIL- & $157.6 \pm 18.4$ & $1,655.4 \pm 178.3$ & $1,840.2 \pm 654.5$ & 0.0001 & 0.0001 & \\
\hline VEGFa & $140.5 \pm 12.7$ & $248.4 \pm 36.2$ & $173.0 \pm 28.2$ & 0.0006 & & \\
\hline
\end{tabular}

${ }^{*} P$-values for controls vs early HPS cases.

${ }^{* *} P$-values for controls vs late HPS cases.

"P-values for late vs early HPS cases.

${ }^{a}$ Values differ significantly only in early serum from non-fatal HPS cases and not in fatal cases.

serum levels of IL-2RA, IL-18, CXCL1, HGF, MCSF, MIF, CXCL9, and SCF were identified (Table 2).

\section{HFRS Cases from Russia}

Serum cytokines of HFRS cases can be divided into two groups, with 22 cytokines being upregulated and 12 cytokines downregulated (Table 3). Sixteen cytokines were significantly upregulated in the early stage of HFRS, while 11 were significantly downregulated as compared to controls. At the late stage of the disease, 18 cytokines were upregulated and 12 downregulated. Those that were downregulated during the convalescent phase differed from those in the early stage. For example, compared to controls, the level of CCL5 changed significantly only during the late stage of the disease, while the serum level of bFGF was significantly downregulated only during the early stage of the disease. When upregulated cytokines were compared, nine cytokines (IL-1 $\beta$, IL-1RA, IL-2, IL-4, IL-6, IL-7, IL-12p75, IFN $\gamma$, and TNF $\alpha$ ) differed significantly between the early and late stage of the disease. Interestingly, the average serum concentrations of these cytokines were higher in the late stage as compared to the early stage of the disease.

\section{HFRS vs HPS Cytokine Profile}

While the serum levels of 12 cytokines were lower in early HFRS relative to the controls, no cytokines were observed to be downregulated in HPS cases (Tables 1 and 3, respectively). All 12 cytokines downregulated during the early stage of HFRS were upregulated in HPS cases. 
TABLE 2 | Serum cytokine levels in survived and fatal hantavirus pulmonary syndrome (HPS) cases.

\begin{tabular}{|c|c|c|c|c|c|}
\hline Analyte & Control $(n=10 ; \mathrm{pg} / \mathrm{ml})$ & Survived $(n=29 ; \mathrm{pg} / \mathrm{ml})$ & Fatal $(n=7 ; \mathrm{pg} / \mathrm{ml})$ & $P^{*}$ & $P^{\star \star}$ \\
\hline$\| \mathrm{L}-1 \alpha$ & $86.7 \pm 9.1$ & $393.3 \pm 10.7$ & $404.2 \pm 15.9$ & 0.0001 & \\
\hline IL-2RA & $138.7 \pm 12.2$ & $1,375 \pm 122.6$ & $1,903.6 \pm 240.5$ & 0.0001 & 0.04 \\
\hline IL-3 & $82.1 \pm 11.7$ & $2,444.9 \pm 215.4$ & $2,813.8 \pm 287.4$ & 0.0001 & \\
\hline $\mathrm{IL}-6^{\mathrm{a}}$ & $74.2 \pm 18.7$ & $137.7 \pm 54.4$ & $422.9 \pm 367.4$ & 0.01 & \\
\hline IL-9 & $25.8 \pm 3.1$ & $85.4 \pm 20.5$ & $94.9 \pm 55.1$ & 0.001 & \\
\hline $\mathrm{IL}-10$ & $45.2 \pm 4.9$ & $186.8 \pm 101.8$ & $92.8 \pm 17.9$ & 0.0026 & \\
\hline IL-12p40 & $159.7 \pm 23.5$ & $4,295.9 \pm 513.1$ & $5,776.9 \pm 1,102.2$ & 0.0001 & \\
\hline IL-12p75 & $44.6 \pm 4.6$ & $100 \pm 14.7$ & $73.6 \pm 9.5$ & 0.03 & \\
\hline $\mathrm{IL}-13$ & $52.4 \pm 4.0$ & $97.4 \pm 21.0$ & $76.3 \pm 4.8$ & 0.04 & \\
\hline $\mathrm{IL}-15$ & $33.2 \pm 2.7$ & $68.2 \pm 15.0$ & $51.5 \pm 5.5$ & 0.02 & \\
\hline $\mathrm{IL}-16$ & $169.3 \pm 35.7$ & $2,759.3 \pm 295.2$ & $3,848.4 \pm 696.9$ & 0.0001 & \\
\hline IL-18 & $444.4 \pm 71.3$ & $854.2 \pm 60.3$ & $1,640.7 \pm 532.9$ & 0.0001 & 0.03 \\
\hline CCL2 & $173.4 \pm 17.0$ & $256.2 \pm 34.7$ & $313.4 \pm 104.5$ & 0.02 & \\
\hline CCL7 & $128.9 \pm 22.6$ & $455.3 \pm 71.4$ & $550.4 \pm 139.7$ & 0.0001 & \\
\hline CXCL1 & $404.9 \pm 69.3$ & $1,181.5 \pm 100.4$ & $2,283.3 \pm 734.4$ & 0.0001 & 0.03 \\
\hline CXCL9 & $734.8 \pm 140.5$ & $1,949.5 \pm 136.5$ & $2,822.3 \pm 306.1$ & 0.0001 & 0.006 \\
\hline CXCL10 & $415.3 \pm 77.5$ & $2,383.9 \pm 600.8$ & $3,175.6 \pm 1,400.3$ & 0.0001 & \\
\hline CXCL12 & $213.7 \pm 23.9$ & $3,577.9 \pm 116.3$ & $3,865.8 \pm 145.5$ & 0.0001 & \\
\hline bNGF & $79.9 \pm 10.3$ & $278.3 \pm 16.7$ & $258.6 \pm 5.3$ & 0.0001 & \\
\hline GMCFS & $42.9 \pm 5.9$ & $174.6 \pm 68.9$ & $82.8 \pm 19.4$ & 0.03 & \\
\hline HGF & $705.6 \pm 134.5$ & $3,059.5 \pm 333.7$ & $7,513.2 \pm 1,896.8$ & 0.0001 & 0.002 \\
\hline $\mathrm{IFN} \alpha$ & $71.0 \pm 7.3$ & $466.9 \pm 30.7$ & $528.6 \pm 23.7$ & 0.0001 & \\
\hline $\mathrm{IFN} \gamma$ & $69.0 \pm 11.9$ & $190.1 \pm 41.9$ & $175.3 \pm 27.9$ & 0.003 & \\
\hline LIF & $177.7 \pm 24.0$ & $742.5 \pm 57.2$ & $838.4 \pm 63.7$ & 0.0001 & \\
\hline MCSF & $206.3 \pm 30.9$ & $876.9 \pm 59.5$ & $1,365.4 \pm 210.9$ & 0.0001 & 0.006 \\
\hline MIF & $299.5 \pm 59.1$ & $1,781.1 \pm 308.5$ & $4,087.6 \pm 1,121.5$ & 0.0001 & 0.01 \\
\hline SCF & $268.3 \pm 39.9$ & $1,308.1 \pm 78.8$ & $1,697 \pm 214.2$ & 0.0001 & 0.04 \\
\hline SCGFb & $2,037.4 \pm 370.3$ & $37,609 \pm 1,796.5$ & $38,632.7 \pm 1,168.9$ & 0.0001 & \\
\hline $\mathrm{TNF} \beta$ & $84.3 \pm 11.0$ & $264.1 \pm 20.7$ & $282.9 \pm 36.1$ & 0.0001 & \\
\hline TRAIL & $157.6 \pm 18.4$ & $1,655.4 \pm 178.3$ & $1,954.9 \pm 216.2$ & 0.0001 & \\
\hline
\end{tabular}

*P-values for fatal HPS cases vs controls.

${ }^{* *} P$-values for fatal vs non-fatal HPS cases.

aValues differ significantly only in fatal HPS cases and not in early non-fatal cases.

Twenty-two cytokines were upregulated in the sera of earlystage HFRS cases, while 41 cytokines were upregulated in early HPS cases (Tables 1 and 3, respectively). Furthermore, only 14 cytokines were upregulated in both HFRS and HPS cases at the early stage (IL-1RA, IL-2, IL-4, IL-7, IL-12p40, IL-12p75, IL-13, IL-16, CXCL9, CXCL10, CXCL12, MIF, SCGFb, and VEGF). As the disease progressed, 17 cytokines were upregulated in HFRS cases, while a much larger group of cytokines, total of 35, was upregulated in HPS cases (Tables 1 and 3, respectively). Among these cytokines, 13 (IL-3, IL-4, IL-7, IL-12p40, IL-13, IL-16, CCL4, CXCL10, CXCL12, GMCSF, IFN $\gamma$, MIF, and SCGFb) were upregulated in the late stages of both HFRS and HPS. It should be noted that the profiles of overlapping cytokines differed in the late stages of HFRS and HPS as compared to that during the early phases of the disease. Only seven cytokines (IL-13, CXCL10, IL-12p40, IL-16, MIF, SCGFb, and CXCL12) were upregulated in early and late stages of HFRS and HPS, while levels of IL-12p75 and CXCL9 remained elevated only in late-stage HPS samples.

\section{FANTOM5 Analysis}

FANTOM5 analysis identified CXCL12 as the most upregulated cytokine in the serum of HPS cases. CXCL12 is induced in response to strong pro-inflammatory stimuli such as TNF $\alpha$ and IL-1 (33). CXCL12 is produced by a plethora of cells including endothelial cells, smooth muscle cells, and macrophages; however, platelets are also a major source of this cytokine in circulation (34-38). It has been shown that CXCL12 increases angiogenesis by binding to heparan sulfate proteoglycans on endothelial cells (33). Therefore, it could be suggested that HPS cases are characterized by increased angiogenesis, possibly due to endothelial damage.

Hemorrhagic fever with renal syndrome cases were characterized by a strong expression of MIF, IL-12p40, IL-3, IL-16, CXCL9, CCL27, CXCL1, and HGF. On the contrary, upregulation of MIF, IL-12p40, IL-3, and IL-16 was modest in HPS, while activation of CXCL12 expression was the characteristic feature of HPS. This observation suggests that virus strain-based reactions to hantavirus infection contributes to the profile. Strong upregulation of IL-12p40, CXCL9, IL-16, and CCL27, mainly produced by activated mononuclear leukocytes including lymphocytes, monocytes, and dendritic cells, are suggestive of a role for mononuclear leukocytes in pathogenesis of HFRS.

\section{IPA Analysis of Serum Cytokine Profile in HFRS and HPS}

Differentially expressed serum cytokines levels for HFRS and HPS cases, as well as fatal and non-fatal HPS cases, were further investigated by functional pathway analysis using two independent pathway enrichment analysis engines. First, the HFRS and 
TABLE 3 | Serum cytokine levels in early and late hemorrhagic fever with renal syndrome (HFRS) cases.

\begin{tabular}{|c|c|c|c|c|c|c|}
\hline Analyte & Control $(n=45)$ & HFRS early $(n=34)$ & HFRS late $(n=33)$ & $P^{*}$ & $P^{* *}$ & $P^{\#}$ \\
\hline \multicolumn{7}{|c|}{ Upregulated cytokines } \\
\hline $\mathrm{IL}-1 \beta$ & $32.04 \pm 4.7$ & $52.5 \pm 5.9$ & $96.2 \pm 19.6$ & 0.007 & 0.0001 & 0.03 \\
\hline IL-1RA & $327.4 \pm 62.4$ & $330.4 \pm 18.5$ & $589.8 \pm 118.5$ & & 0.03 & 0.03 \\
\hline IL-2 & $17.5 \pm 1.7$ & $30.9 \pm 0.9$ & $39.6 \pm 3.8$ & & 0.0001 & 0.03 \\
\hline $\mathrm{IL}-3$ & $82.1 \pm 11.7$ & $504.7 \pm 53.8$ & $464.3 \pm 59.7$ & 0.0001 & 0.0001 & \\
\hline IL-4 & $8.8 \pm 0.6$ & $10.9 \pm 0.1$ & $12.1 \pm 0.5$ & 0.0001 & 0.0003 & 0.04 \\
\hline IL-5 & $18.9 \pm 1.7$ & $40.9 \pm 0.2$ & $40.9 \pm 0.2$ & 0.0001 & 0.0001 & \\
\hline IL-6 & $74.2 \pm 18.7$ & $71.8 \pm 4.5$ & $102.8 \pm 14.8$ & & & 0.04 \\
\hline IL-7 & $67.9 \pm 4.9$ & $88.3 \pm 0.2$ & $91.0 \pm 1.3$ & 0.001 & 0.0004 & 0.04 \\
\hline IL-12p40 & $159.7 \pm 23.6$ & $915.6 \pm 100.9$ & $890.0 \pm 105.9$ & 0.0001 & 0.0001 & \\
\hline IL-12p75 & $44.6 \pm 4.6$ & $29.8 \pm 1.7$ & $43.4 \pm 5.4$ & 0.01 & & 0.01 \\
\hline IL-13 & $52.4 \pm 4.1$ & $73.4 \pm 0.2$ & $75.0 \pm 0.8$ & 0.0001 & 0.0001 & 0.05 \\
\hline IL-16 & $169.3 \pm 35.8$ & $830.1 \pm 134.3$ & $544.1 \pm 108.4$ & 0.0001 & 0.0001 & \\
\hline CCL4 & $136.6 \pm 14.4$ & $227.7 \pm 1.9$ & $225.6 \pm 32.7$ & 0.0008 & 0.005 & \\
\hline CXCL9 & $734.8 \pm 140.5$ & $2,741.3 \pm 1,228.9$ & $1,293.9 \pm 328.1$ & 0.03 & & \\
\hline CXCL10 & $415.3 \pm 77.5$ & $2,057.5 \pm 405.1$ & $1,802.4 \pm 408.4$ & 0.0001 & 0.0001 & \\
\hline CXCL12 & $213.7 \pm 23.9$ & $384.0 \pm 5.9$ & $383.5 \pm 7.1$ & 0.0001 & 0.0001 & \\
\hline GMCSF & $42.9 \pm 5.9$ & $60.9 \pm 7.4$ & $77.9 \pm 9.9$ & & 0.001 & \\
\hline $\mathrm{IFN} \gamma$ & $69 \pm 11.9$ & $67.5 \pm 16.2$ & $488.2 \pm 115.1$ & & 0.0001 & 0.0004 \\
\hline MIF & $229.5 \pm 59.1$ & $4,615.1 \pm 941.4$ & $2,901.3 \pm 740.9$ & 0.0001 & 0.0001 & \\
\hline SCGFb & $2,037.4 \pm 370.3$ & $11,926.7 \pm 1,322.5$ & $10,474.7 \pm 1,372.6$ & 0.0001 & 0.0001 & \\
\hline TNF $\alpha$ & $84.4 \pm 10.3$ & $62.1 \pm 1.2$ & $101.9 \pm 20.2$ & & & 0.04 \\
\hline VEGF & $140.5 \pm 12.7$ & $215.9 \pm 18.2$ & $251.5 \pm 26.3$ & 0.0006 & 0.0001 & \\
\hline \multicolumn{7}{|c|}{ Downregulated cytokines } \\
\hline $\mathrm{IL}-1 \alpha$ & $86.7 \pm 9.1$ & $30.5 \pm 0.9$ & $30.1 \pm 1.2$ & 0.0001 & 0.0001 & \\
\hline IL-2RA & $138.7 \pm 12.2$ & $102.4 \pm 6.7$ & $99.8 \pm 4.3$ & 0.02 & 0.02 & \\
\hline IL-18 & $444.4 \pm 71.3$ & $114.4 \pm 8.5$ & $121.9 \pm 12.2$ & 0.0001 & 0.0007 & \\
\hline CCL5 & $6,348.9 \pm 581.2$ & $5,072.2 \pm 265.2$ & $4,768.8 \pm 245.1$ & & 0.04 & \\
\hline CCL27 & $836.3 \pm 133.7$ & $335.8 \pm 42.5$ & $266.3 \pm 34.1$ & 0.0001 & 0.001 & \\
\hline CXCL1 & $404.8 \pm 69.4$ & $162.3 \pm 17.8$ & $154.1 \pm 19.9$ & 0.007 & 0.006 & \\
\hline bFGF & $42.3 \pm 5.4$ & $15.9 \pm 1.7$ & $30.6 \pm 5.7$ & 0.0002 & & 0.01 \\
\hline bNGF & $79.9 \pm 10.3$ & $22.9 \pm 0.5$ & $22.9 \pm 0.8$ & 0.0001 & 0.0001 & \\
\hline LIF & $177.7 \pm 24.0$ & $85.5 \pm 2.6$ & $85.5 \pm 2.9$ & 0.003 & 0.003 & \\
\hline MCSF & $206.3 \pm 30.9$ & $117.5 \pm 12.9$ & $100.8 \pm 10.6$ & 0.02 & 0.01 & \\
\hline SCF & $268.3 \pm 39.9$ & $164.7 \pm 17.9$ & $146.3 \pm 16.4$ & 0.05 & 0.02 & \\
\hline TNF $\beta$ & $84.3 \pm 18.4$ & $35.1 \pm 0.7$ & $34.9 \pm 0.7$ & 0.0006 & 0.0007 & \\
\hline
\end{tabular}

${ }^{*}$ P-values for controls vs early HFRS cases.

${ }^{* *} P$-values controls vs late HFRS cases.

"P-values for early and late HFRS cases.

HPS cytokine profiles of early samples were compared. The most important canonical pathways altered in the early phase of HFRS include cytokine-cytokine receptor interaction chemokine signaling, MAPK signaling, and neurotropin signaling pathways. For early HPS, a larger number of pathways were changed including cytokine-cytokine receptor interaction, RIG-I-like signaling, chemokine signaling, STAT signaling, cytosolic DNA-sensing, regulation of autophagy, TOLL-like receptor signaling, and NOD-like receptor signaling pathways. Additionally, pathways regulating antigen processing and presentation, as well as NK-cell-meditated cytotoxicity, were identified as significant in early-stage HPS cases.

Serum cytokine profile analysis of samples from late phase of HFRS did not reveal significantly altered pathways as compared to healthy controls. Analysis of serum samples from the late phase of HPS revealed fewer pathways as compared to that during the early phase of the disease and included NOD-like receptor signaling, cytokine-cytokine receptor interaction and RIG-I-like receptor signaling. When fatal and non-fatal HPS cases were compared, the cytokine-cytokine receptor interaction and JAK-STAT signaling pathways had significant differences. The serum cytokine profiles suggest that the JAK-STAT signaling pathway was suppressed in fatal cases as compared to non-fatal HPS cases.

\section{DISCUSSION}

Hemorrhagic fever with renal syndrome and HPS are acute infectious diseases caused by a distinct group of hantaviruses circulating among small rodents. In Tatarstan, HFRS is associated with infection by Arvicolinae-borne hantaviruses and HPS is a disease caused by Sigmodontinae-associated hantaviruses (39). Although clinically HPS and HFRS may overlap (40-42), pneumonia and cardiovascular insufficiency are central to HPS, while renal involvement and dysregulation in blood coagulation being the main sequelae in HFRS. The mortality rates also differ, with HPS having a higher mortality rate than HFRS, 39.3 vs 0.4 , respectively $(6,43)$. Although there are distinct clinical 
presentations associated with Sigmadontinae- and Arvicolinaeborn hantaviruses, these viruses are non-cytopathic in vitro $(21,22)$. Furthermore, no virus replication-associated cell death has been reported in tissues collected postmortem from HFRS and HPS cases $(23,24)$, suggesting that a response to infection plays a major role in the pathogenesis of these diseases. Differences in serum cytokine expression are one of the most consistent findings in HPS and HFRS. Many studies have documented a significant upregulation of pro-inflammatory cytokines, leading to the "cytokine storm" hypothesis to explain the pathogenesis of hantavirus-caused diseases.

Our data provide evidence to support the role of cytokines in HPS and HFRS pathogenesis. Striking differences in cytokine profiles were found between HPS and HFRS samples. HPS, the more severe form of hantavirus zoonosis, is characterized by upregulated serum cytokine levels, with no cytokines being downregulated (Tables 1 and 3). On the contrary, HFRS cases were characterized by dichotomy in the serum cytokine profile (Table 3), with cytokines being both upregulated and downregulated. Additionally, we observed higher number of cytokines upregulated in HPS as compared to HFRS, 41 vs 22, respectively. These data suggest that the severity of the disease could be associated with a "cytokine storm" as the body's response to infection.

Our data support previous observations that chemokines promoting mononuclear leukocyte migration are upregulated in hantavirus-infected patients (28). In this study, upregulation of CXCL9 and CXCL10 were characteristic for both HPS and HFRS throughout the course of the disease. Here, we extend the knowledge of chemokine expression in HPS and HFRS. For example, increased serum levels of IL-16, a chemoattractant acting on activated T lymphocytes, was found in both HPS and HFRS (44). Additionally, we have shown that CXCL12, a potent chemoattractant for mononuclear leukocytes, is upregulated in patients with hantavirus infection $(45,46)$. Furthermore, there were chemokines uniquely upregulated in HPS cases including CCL2, CXCL1, and CCL7. These cytokines are known to promote tissue migration of monocytes, memory $\mathrm{T}$ cells, and dendritic cells $(47,48)$.

CXCL1, a neutrophil chemoattractant produced by activated macrophages and epithelial cells $(49,50)$, was upregulated in HPS cases, while being downregulated in HFRS samples. This suggests that although leukocyte tissue infiltration is characteristic to both HPS and HFRS, there is a mixed phenotype of migrating immune effector cells in HPS cases including neutrophils and mononuclear leukocytes. Since neutrophil migration is often associated with tissue damage and vascular leakage, the role of neutrophil migration in HPS pathogenesis requires further investigation.

Early activation of leukocytes is evident in the serum of HPS cases and differs from HFRS. For example, IL-15 is upregulated only in HPS, suggesting activation and proliferation of T cells and NK cells. IL-15 functions through JAK kinase, STAT3, STAT5, and STAT6, which is supported by IPA analysis. Additionally, activation of GCSF was detected only in HPS cases, at both early and late stages of the disease, suggesting sustained proliferation, differentiation, and survival of monocytes and macrophages in
HPS. Elevated serum levels of IL-3, SCGFb, and SCF in HPS indicates increased proliferation of bone marrow progenitors, and upregulation of M-CSF and GM-CSF further suggests that myeloid progenitor proliferation is increased in HPS. Also, it should be noted that levels of IFN- $\gamma$ remained persistently increased in HPS cases throughout the course of the disease, whereas IFN- $\gamma$ levels were upregulated during late -phase HFRS, consistent with our previous observations (28). IFN- $\gamma$ is associated with activation of Th1-type immune responses and is produced by activated $\mathrm{T}$ helper cells, cytotoxic $\mathrm{T}$ lymphocytes (CTL), and NK cells.

Our findings that IL-18 was upregulated in the serum of HPS cases, while being downregulated in the serum from those with HFRS, further corroborate the activation of Th1. IL-18 is a strong activator of Th1-type immunity, and alone or together with IL-12, upregulates the production of IFN $\gamma$ by T cells and NK cells (51). These data suggest that early activation of NK cells and CTL is characteristic to HPS, while being less pronounced in HFRS. Excessive activation of NK cells and CTL can cause tissue damage, which has been shown to play a role in the pathogenesis of organ damage $(52,53)$. Recently, Prescott et al. suggested that an adaptive immune response has no influence on hantavirus replication or disease pathogenesis, based on studies using a hamster model of HPS (54). However, clinical studies indicate the potential role of innate and adaptive immune responses in disease pathogenesis (55-58). Our data support the role of adaptive immune responses in the pathogenesis of hantavirus infection. Also, it could be suggested that early strong activation of Th1-type immune response may be associated with severe clinical presentations.

A strong inflammatory response is evident based on serum cytokine profiles for HFRS and HPS. For instance, upregulation of pro-inflammatory cytokines such as IL-1 $\beta$, IL-6, TNF $\alpha$, and MIF were found inHFRS and HPS cases. Although the elevation of IL-1 $\beta$, IL-6, and TNF $\alpha$ in hantavirus cases is well documented, upregulation of serum MIF has not been described previously for either HPS or HFRS cases. MIF is a multifactorial cytokine with a strong pro-inflammatory activity, suggesting a role for MIF in increasing vascular permeability and tissue migration of immune effector cells. Furthermore, increased serum VEGF levels in HFRS and HPS cases also suggest that this pro-inflammatory activity can be promoted by MIF-induced upregulation of metalloproteases, resulting in degradation of the extracellular matrix (59-61). Additionally, MIF can facilitate leukocyte transendothelial migration by upregulation of the adhesion molecules VCAM-1 and ICAM-1 on endothelial cells and monocytes (62, 63). Although HFRS and HPS are characterized by an increased pro-inflammatory serum profile, as described above, the upregulation of IL-18 was unique to HPS. IL-18 has been classified as a cytokine promoting severe inflammatory reactions (64-66). Therefore, we suggest that the clinical presentation of HPS may be due, in part, to the high serum levels of IL-18. It has been demonstrated that IL-18 activation is regulated through the NOD-like receptor regulated pathway $(67,68)$. IPA analysis of serum cytokine profiles revealed NOD-like pathway involvement only in HPS cases, further suggesting a role for this pathway in HPS pathogenesis. 
Our analysis of serum cytokine profiles in HPS and HFRS cases suggests that although HPS and HFRS share many features, there are distinct cytokine profiles differentiating these diseases. They include (1) a severe inflammatory response in HPS cases, where IL-18 may play a central role, (2) a robust and early activation of Th1-type immune response in HPS cases as compared to HFRS, and (3) a strong activation of an innate immune response, especially NK cells in HPS cases. The cytokine profiles are suggestive of degradation of the extracellular matrix, increased mononuclear leukocyte proliferation, and transendothelial migration in both HPS and HFRS.

\section{ETHICS STATEMENT}

Samples collected in the Russian Federation were done so under a protocol approved by the Institutional Review Board of the Kazan Federal University and informed consent was obtained from each respective subject according to the guidelines approved under this protocol (Article 20, Federal Law "Protection of Health Right of Citizens of Russian Federation" N323-FZ, 11.21.2011). Sample collection in Argentina was made under a protocol approved by the Institutional Review Board of the Instituto Nacional de Enfermedades Virales Humanas Argentina.

\section{REFERENCES}

1. Jonsson CB, Figueiredo LT, Vapalahti O. A global perspective on hantavirus ecology, epidemiology, and disease. Clin Microbiol Rev (2010) 23(2):412-41. doi:10.1128/CMR.00062-09

2. Tappero JW, Khan AS, Pinner RW, Wenger JD, Graber JM, Armstrong LR, et al. Utility of emergency, telephone-based national surveillance for hantavirus pulmonary syndrome. Hantavirus task force. JAMA (1996) 275(5):398-400. doi:10.1001/jama.275.5.398

3. Calderón G, Pini N, Bolpe J, Levis S, Mills J, Segura E, et al. Hantavirus reservoir hosts associated with peridomestic habitats in Argentina. Emerg Infect Dis (1999) 5(6):792-7. doi:10.3201/eid0506.990608

4. Heyman P, Vaheri A, ENIVD Members. Situation of hantavirus infections and haemorrhagic fever with renal syndrome in European countries as of December 2006. Euro Surveill (2008) 13(28):18925.

5. Tkachenko EA, Bernshtein AD, Dzagurova TK, Morozov VG, Slonova RA, Ivanov LI, et al. [Actual problems of hemorrhagic fever with renal syndrome]. Zh Mikrobiol Epidemiol Immunobiol (2013) 1:51-8.

6. Hjertqvist M, Klein SL, Ahlm C, Klingstrom J. Mortality rate patterns for hemorrhagic fever with renal syndrome caused by Puumala virus. Emerg Infect Dis (2010) 16(10):1584-6. doi:10.3201/eid1610.100242

7. Makary P, Kanerva M, Ollgren J, Virtanen MJ, Vapalahti O, Lyytikäinen O. Disease burden of Puumala virus infections, 1995-2008. Epidemiol Infect (2010) 138(10):1484-92. doi:10.1017/S0950268810000087

8. Garanina SB, Platonov AE, Zhuravlev VI, Murashkina AN, Yakimenko VV, Korneev AG, et al. Genetic diversity and geographic distribution of hantaviruses in Russia. Zoonoses Public Health (2009) 56(6-7):297-309. doi:10.1111/j. 1863-2378.2008.01210.x

9. KabweN E, DavidyukS Y, Morzunov P, ShakirovaV VG, AnokhinG A, IsaevaRS, et al. Genetic characterization of small (s)-segment genome Puumala virus strain Kazan. BioNanoScience (2016). doi:10.1007/s12668-016-0338-2

10. Niklasson BS. Haemorrhagic fever with renal syndrome, virological and epidemiological aspects. Pediatr Nephrol (1992) 6(2):201-4. doi:10.1007/BF00866318

11. Martinez-Valdebenito C, Calvo M, Vial C, Mansilla R, Marco C, Palma RE, et al. Person-to-person household and nosocomial transmission of Andes hantavirus, Southern Chile, 2011. Emerg Infect Dis (2014) 20(10):1629-36. doi:10.3201/eid2010.140353

\section{AUTHOR CONTRIBUTIONS}

SK: collecting data, data analysis, and writing manuscript. SL: HPS serum sample preparation, Argentina site. SM: HPS serum sample preparation, USA site. EM: HFRS samples preparation and collecting data, Russia site. VA: clinical data analysis and contribution into the discussion. OG: IPA analysis and contribution into discussion. SJ: manuscript editing and study team coordinator. VL: manuscript editing and contribution into discussion. AR: project management and coordination between Argentina, USA, Russia, and Japan sites and intellectual contribution into discussion.

\section{FUNDING}

This study was supported by Russian Science Foundation grant 15-14-00016. The work is performed according to the Russian Government Program of Competitive Growth of Kazan Federal University and subsidy allocated to Kazan Federal University for the state assignment in the sphere of scientific activities. Some of the experiments were conducted with support of Federal Center of Collective Use and Pharmaceutical Research and Education Center, Kazan (Volga Region) Federal University, Kazan, Russia. We thank Dr. Alistair R. Forrest for help with data analysis.

12. Padula PJ, Edelstein A, Miguel SD, López NM, Rossi CM, Rabinovich RD [Epidemic outbreak of Hantavirus pulmonary syndrome in Argentina. Molecular evidence of person to person transmission of Andes virus]. Medicina (B Aires) (1998) 58(Suppl 1):27-36.

13. Enria DA, Briggiler AM, Pini N, Levis S. Clinical manifestations of New World hantaviruses. Curr Top Microbiol Immunol (2001) 256:117-34. doi:10.1007/978-3-642-56753-7_7

14. Pini N. Hantavirus pulmonary syndrome in Latin America. Curr Opin Infect Dis (2004) 17(5):427-31. doi:10.1097/00001432-200410000-00007

15. Figueiredo LTM, Moreli ML, de-Sousa RLM, Borges AA, de-Figueiredo GG, Machado AM, et al. Hantavirus Pulmonary Syndrome, Central Plateau, Southeastern, and Southern Brazil. Emerg Infect Dis (2009) 15(4):561-7. doi:10.3201/eid1504.080289

16. Settergren B, Leschinskaya E, Zagidullin I, Fazlyeva R, Khunafina D, Niklasson B. Hemorrhagic fever with renal syndrome: comparison of clinical course in Sweden and in the Western Soviet Union. Scand J Infect Dis (1991) 23(5):549-52. doi:10.3109/00365549109105176

17. Peco-Antić A, Popović-Rolović M, Gligić A, Popović D, Jovanović O, Kostić M. Clinical characteristics of haemorrhagic fever with renal syndrome in children. Pediatr Nephrol (1992) 6(4):335-8. doi:10.1007/ BF00869727

18. Bren AF, Pavlovcic SK, Koselj M, Kovac J, Kandus A, Kveder R. Acute renal failure due to hemorrhagic fever with renal syndrome. Ren Fail (1996) 18(4):635-8. doi:10.3109/08860229609047688

19. Settergren B. Nephropathia epidemica (hemorrhagic fever with renal syndrome) in Scandinavia. Rev Infect Dis (1991) 13(4):736-44. doi:10.1093/ clinids/13.4.736

20. Mäkelä S, Ala-Houhala I, Mustonen J, Koivisto AM, Kouri T, Turjanmaa V, et al. Renal function and blood pressure five years after Puumala virusinduced nephropathy. Kidney Int (2000) 58(4):1711-8. doi:10.1046/j.15231755.2000.00332.x

21. Khaiboullina SF, Netski DM, Krumpe P, St Jeor SC. Effects of tumor necrosis factor alpha on sin nombre virus infection in vitro. J Virol (2000) 74(24):11966-71. doi:10.1128/JVI.74.24.11966-11971.2000

22. Temonen M, Vapalahti O, Holthöfer H, Brummer-Korvenkontio M, Vaheri A, Lankinen H. Susceptibility of human cells to Puumala virus infection. J Gen Virol (1993) 74(Pt 3):515-8. doi:10.1099/0022-1317-74-3-515 
23. Zaki SR, Greer PW, Coffield LM, Goldsmith CS, Nolte KB, Foucar K, et al. Hantavirus pulmonary syndrome. Pathogenesis of an emerging infectious disease. Am J Pathol (1995) 146(3):552-79.

24. Temonen M, Mustonen J, Helin H, Pasternack A, Vaheri A, Holthöfer H. Cytokines, adhesion molecules, and cellular infiltration in nephropathia epidemica kidneys: an immunohistochemical study. Clin Immunol Immunopathol (1996) 78(1):47-55. doi:10.1006/clin.1996.0007

25. Colby TV,Zaki SR, Feddersen RM, Nolte KB. Hantavirus pulmonary syndrome is distinguishable from acuteinterstitial pneumonia.Arch PatholLabMed(2000) 124(10):1463-6. doi:10.1043/0003-9985(2000)124<1463:HPSIDF>2.0.CO;2

26. Mori M, Rothman AL, Kurane I, Montoya JM, Nolte KB, Norman JE, et al. High levels of cytokine-producing cells in the lung tissues of patients with fatal hantavirus pulmonary syndrome. J Infect Dis (1999) 179(2):295-302. doi:10.1086/314597

27. Sadeghi M, Eckerle I, Daniel V, Burkhardt U, Opelz G, Schnitzler P. Cytokine expression during early and late phase of acute Puumala hantavirus infection. BMC Immunol (2011) 12:65. doi:10.1186/1471-2172-12-65

28. Khaiboullina SF, Martynova EV, Khamidullina ZL, Lapteva EV, Nikolaeva IV, Anokhin VV, et al. Upregulation of IFN-gamma and IL-12 is associated with a milder form of hantavirus hemorrhagic fever with renal syndrome. Eur J Clin Microbiol Infect Dis (2014) 33(12):2149-56. doi:10.1007/s10096-014-2176-x

29. BorgesAA,CamposGM,MoreliML,MoroSouzaRL,SaggioroFP,FigueiredoGG, et al. Role of mixed Th1 and Th2 serum cytokines on pathogenesis and prognosis of hantavirus pulmonary syndrome. Microbes Infect (2008) 10(10-11):1150-7. doi:10.1016/j.micinf.2008.06.006

30. Saksida A, Wraber B, Avsic-Zupanc T. Serum levels of inflammatory and regulatory cytokines in patients with hemorrhagic fever with renal syndrome. BMC Infect Dis (2011) 11:142. doi:10.1186/1471-2334-11-142

31. Zupanc TA, Korva M, Markotic A. HFRS and hantaviruses in the Balkans/South-East Europe. Virus Res (2014) 187:27-33. doi:10.1016/j. virusres.2013.12.042

32. Huang DW, Sherman BT, Lempicki RA. Systematic and integrative analysis of large gene lists using DAVID bioinformatics resources. Nat Protoc (2009) 4(1):44-57. doi:10.1038/nprot.2008.211

33. Santiago B, Baleux F, Palao G, Gutiérrez-Cañas I, Ramírez JC, ArenzanaSeisdedos F, et al. CXCL12 is displayed by rheumatoid endothelial cells through its basic amino-terminal motif on heparan sulfate proteoglycans. Arthritis Res Ther (2006) 8(2):R43. doi:10.1186/ar1900

34. Ding L, Morrison SJ. Haematopoietic stem cells and early lymphoid progenitors occupy distinct bone marrow niches. Nature (2013) 495(7440):231-5. doi:10.1038/nature 11885

35. Gear ARL, Camerini D. Platelet chemokines and chemokine receptors: linking hemostasis, inflammation, and host defense. Microcirculation (2003) 10(3-4):335-50. doi:10.1038/sj.mn.7800198

36. Schober A, Karshovska E, Zernecke A, Weber C. SDF-1alpha-mediated tissue repair by stem cells: a promising tool in cardiovascular medicine? Trends Cardiovasc Med (2006) 16(4):103-8. doi:10.1016/j.tcm.2006.01.006

37. Abi-Younes S, Si-Tahar M, Luster AD. The CC chemokines MDC and TARC induce platelet activation via CCR4. Thromb Res (2001) 101(4):279-89. doi:10.1016/S0049-3848(00)00402-3

38. Chatterjee M, Gawaz M. Platelet-derived CXCL12 (SDF-1alpha): basic mechanisms and clinical implications. J Thromb Haemost (2013) 11(11):1954-67. doi:10.1111/jth.12404

39. Khaiboullina SF, Morzunov SP, St Jeor SC. Hantaviruses: molecular biology, evolution and pathogenesis. Curr Mol Med (2005) 5(8):773-90. doi:10.2174/156652405774962317

40. Clement J, Maes P, Lagrou K, Van Ranst M, Lameire N. A unifying hypothesis and a single name for a complex globally emerging infection: hantavirus disease. Eur JClin Microbiol Infect Dis (2012) 31(1):1-5. doi:10.1007/ s10096-011-1456-y

41. Gizzi M, Delaere B, Weynand B, Clement J, Maes P, Vergote V, et al. Another case of "European hantavirus pulmonary syndrome" with severe lung, prior to kidney, involvement, and diagnosed by viral inclusions in lung macrophages. Eur J Clin Microbiol Infect Dis (2013) 32(10):1341-5. doi:10.1007/ s10096-013-1885-x

42. Clement J, Maes P, Van Ranst M. Hemorrhagic fever with renal syndrome in the new, and hantavirus pulmonary syndrome in the Old World: paradi(se) gm lost or regained? Virus Res (2014) 187:55-8. doi:10.1016/j.virusres.2013. 12.036
43. da Rosa Elkhoury M, da Silva Mendes W, Waldman EA, Dias JP, Carmo EH, Fernando da Costa Vasconcelos P. Hantavirus pulmonary syndrome: prognostic factors for death in reported cases in Brazil. Trans $R$ Soc Trop Med Hyg (2012) 106(5):298-302. doi:10.1016/j.trstmh.2012.01.002

44. Cruikshank W, Little F. Interleukin-16: the ins and outs of regulating T-cell activation. Crit Rev Immunol (2008) 28(6):467-83. doi:10.1615/CritRevImmunol. v28.i6.10

45. Sánchez-Martín L, Estecha A, Samaniego R, Sánchez-Ramón S, Vega MÁ, Sánchez-Mateos P. The chemokine CXCL12 regulates monocytemacrophage differentiation and RUNX3 expression. Blood (2011) 117(1): 88-97. doi:10.1182/blood-2009-12-258186

46. D’Apuzzo M, Rolink A, Loetscher M, Hoxie JA, Clark-Lewis I, Melchers F, et al. The chemokine SDF-1, stromal cell-derived factor 1, attracts early stage B cell precursors via the chemokine receptor CXCR4. Eur J Immunol (1997) 27(7):1788-93. doi:10.1002/eji.1830270729

47. Roth SJ, Carr MW, Springer TA. C-C chemokines, but not the C-X-C chemokines interleukin-8 and interferon-gamma inducible protein-10, stimulate transendothelial chemotaxis of T lymphocytes. Eur J Immunol (1995) 25(12):3482-8. doi:10.1002/eji.1830251241

48. Proost P, Wuyts A, Van Damme J. Human monocyte chemotactic proteins-2 and -3: structural and functional comparison with MCP-1. JLeukoc Biol (1996) 59(1):67-74.

49. Chintakuntlawar AV, Chodosh J. Chemokine CXCL1/KC and its receptor CXCR2 are responsible for neutrophil chemotaxis in adenoviral keratitis. J Interferon Cytokine Res (2009) 29(10):657-66. doi:10.1089/jir.2009.0006

50. De Filippo K, Dudeck A, Hasenberg M, Nye E, van Rooijen N, Hartmann K, et al. Mast cell and macrophage chemokines CXCL1/CXCL2 control the early stage of neutrophil recruitment during tissue inflammation. Blood (2013) 121(24):4930-7. doi:10.1182/blood-2013-02-486217

51. Tominaga K, Yoshimoto T, Torigoe K, Kurimoto M, Matsui K, Hada T, et al. IL-12 synergizes with IL-18 or IL-1beta for IFN-gamma production from human T cells. Int Immunol (2000) 12(2):151-60. doi:10.1093/intimm/12.2.151

52. Li F, Zhu H, Sun R, Wei H, Tian Z. Natural killer cells are involved in acute lung immune injury caused by respiratory syncytial virus infection. J Virol (2012) 86(4):2251-8. doi:10.1128/JVI.06209-11

53. Sitkovsky MV, Lukashev D, Apasov S, Kojima H, Koshiba M, Caldwell C, et al. Physiological control of immune response and inflammatory tissue damage by hypoxia-inducible factors and adenosine A2A receptors. Annu Rev Immunol (2004) 22:657-82. doi:10.1146/annurev.immunol.22.012703.104731

54. Prescott J, Safronetz D, Haddock E, Robertson S, Scott D, Feldmann H. The adaptive immune response does not influence hantavirus disease or persistence in the Syrian hamster. Immunology (2013) 140(2):168-78. doi:10.1111/imm.12116

55. Koivula TT, Tuulasvaara A, Hetemäki I, Mäkelä SM, Mustonen J, Sironen T, et al. Regulatory $\mathrm{T}$ cell response correlates with the severity of human hantavirus infection. J Infect (2014) 68(4):387-94. doi:10.1016/j.jinf.2013.11.007

56. Wang M, Wang J, Zhu Y, Xu Z, Yang K, Yang A, et al. Cellular immune response to Hantaan virus nucleocapsid protein in the acute phase of hemorrhagic fever with renal syndrome: correlation with disease severity. J Infect Dis (2009) 199(2):188-95. doi:10.1086/595834

57. Rasmuson J, Pourazar J, Linderholm M, Sandström T, Blomberg A, Ahlm C. Presence of activated airway T lymphocytes in human Puumala hantavirus disease. Chest (2011) 140(3):715-22. doi:10.1378/chest.10-2791

58. Björkström NK, Lindgren T, Stoltz M, Fauriat C, Braun M, Evander M, et al. Rapid expansion and long-term persistence of elevated NK cell numbers in humans infected with hantavirus. J Exp Med(2011) 208(1):13-21. doi:10.1084/ jem. 20100762

59. Onodera S, Kaneda K, Mizue Y, Koyama Y, Fujinaga M, Nishihira J. Macrophage migration inhibitory factor up-regulates expression of matrix metalloproteinases in synovial fibroblasts of rheumatoid arthritis. J Biol Chem (2000) 275(1):444-50. doi:10.1074/jbc.275.1.444

60. Kong YZ, Yu X, Tang JJ, Ouyang X, Huang XR, Fingerle-Rowson G, et al. Macrophage migration inhibitory factor induces MMP-9 expression: implications for destabilization of human atherosclerotic plaques. Atherosclerosis (2005) 178(1):207-15. doi:10.1016/j.atherosclerosis.2004.08.030

61. Leech M, Metz C, Hall P, Hutchinson P, Gianis K, Smith M, et al. Macrophage migrationinhibitoryfactorinrheumatoidarthritis: evidenceofproinflammatory function and regulation byglucocorticoids. Arthritis Rheum (1999) 42(8):16018. doi:10.1002/1529-0131(199908)42:8<1601::AID-ANR6>3.0.CO;2-B 
62. Lin SG, Yu XY, Chen YX, Huang XR, Metz C, Bucala R, et al. De novo expression of macrophage migration inhibitory factor in atherogenesis in rabbits. Circ Res (2000) 87(12):1202-8. doi:10.1161/01.RES.87.12.1202

63. Amin MA, Haas CS, Zhu K, Mansfield PJ, Kim MJ, Lackowski NP, et al. Migration inhibitory factor up-regulates vascular cell adhesion molecule-1 and intercellular adhesion molecule-1 via Src, PI3 kinase, and NFkappaB. Blood (2006) 107(6):2252-61. doi:10.1182/blood-2005-05-2011

64. Sugimoto T, Ishikawa Y, Yoshimoto T, Hayashi N, Fujimoto J, Nakanishi K. Interleukin 18 acts on memory T helper cells type 1 to induce airway inflammation and hyperresponsiveness in a naive host mouse. J Exp Med (2004) 199(4):535-45. doi:10.1084/jem.20031368

65. Wereszczynska-Siemiatkowska U, Mroczko B, Siemiatkowski A. Serum profiles of interleukin-18 in different severity forms of human acute pancreatitis. Scand J Gastroenterol (2002) 37(9):1097-102. doi:10.1080/ 003655202320378310

66. Cerqueira BA, Boas WV, Zanette AD, Reis MG, Goncalves MS. Increased concentrations of IL-18 and uric acid in sickle cell anemia: contribution of hemolysis, endothelial activation and the inflammasome. Cytokine (2011) 56(2):471-6. doi:10.1016/j.cyto.2011.08.013

67. Johansson SE, Hall H, Björklund J, Höglund P. Broadly impaired NK cell function in non-obese diabetic mice is partially restored by $\mathrm{NK}$ cell activation in vivo and by IL-12/IL-18 in vitro. Int Immunol (2004) 16(1):1-11. doi:10.1093/intimm/dxh002

68. Zaccone P, Phillips J, Conget I, Cooke A, Nicoletti F. IL-18 binding protein fusion construct delays the development of diabetes in adoptive transfer and cyclophosphamide-induced diabetes in NOD mouse. Clin Immunol (2005) 115(1):74-9. doi:10.1016/j.clim.2004.11.007

Conflict of Interest Statement: The authors declare that the research was conducted in the absence of any commercial or financial relationships that could be construed as a potential conflict of interest.

The handling editor declared a shared affiliation, though no other collaboration, with one of the authors (VA) and states that the process nevertheless met the standards of a fair and objective review.

Copyright (C) 2017 Khaiboullina, Levis, Morzunov, Martynova, Anokhin, Gusev, St Jeor, Lombardi and Rizvanov. This is an open-access article distributed under the terms of the Creative Commons Attribution License (CC BY). The use, distribution or reproduction in other forums is permitted, provided the original author(s) or licensor are credited and that the original publication in this journal is cited, in accordance with accepted academic practice. No use, distribution or reproduction is permitted which does not comply with these terms. 